\title{
A Valencior Pars no Defensor Pacis de Marsílio de Pádua ${ }^{1}$
}

\author{
Sérgio Ricardo Strefling ${ }^{2}$
}

\begin{abstract}
RESUMO: Marsílio de Pádua (1280-1343) foi um pensador da Idade Média que escreveu duas obras de filosofia política que influenciaram a modernidade. Este estudo analisa o termo valencior pars, da obra Defensor Pacis. Marsílio parece definir essa parte preponderante como sendo a representação do conjunto dos cidadãos que não tem uma natureza débil. Isso sugere que a valencior pars é tanto qualitativamente superior quanto uma maioria numérica dos cidadãos. $\mathrm{O}$ apelo a uma mistura de consideraçōes quantitativas e qualitativas era familiar no contexto das eleiçôes medievais da Igreja, que geralmente apoiava a parte maior e mais razoável (maior et saniors pars) das instituiçốes eleitorais. Marsílio sugere que a valencior pars pode ser identificada com o costume honrado do governo, entretanto, parece que a mesma corresponde a qualquer parte da coletividade cuja decisão eleitoral é decisiva. Nesse sentido, o filósofo paduano está de acordo com a análise original de Aristóteles.
\end{abstract}

PALAVRAS-CHAVE: Marsílio de Pádua. Representação. Parte preponderante. Política.

\section{ColocaÇáo do PROBlema}

A ideia de representação política expressa pelo filósofo paduano, através da expressão valencior pars, está citada 25 vezes na obra Defensor Pacis ${ }^{3}$ e, algumas vezes, no tratado Defensor Minor. Trata-se de um tema importante e de atualidade na filosofia política e na filosofia moral, pois, do período medieval aos nossos dias, a política e também a ética são pensadas tendo em vista uma visão contratualista, ou seja, não somente o direito divino e o direito

\footnotetext{
${ }^{1}$ Pesquisa realizada com auxílio da CAPES, por meio de bolsa de estágio pós-doutoral sênior, Universidade do Porto, Portugal, 2012-2013.

${ }^{2}$ Doutor em Filosofia. Professor Adjunto do Departamento de Filosofia da Universidade Federal de Pelotas. E-mail: srstrefling@gmail.com.

${ }^{3}$ O Defensor Pacis, publicado em 1324, é a obra onde Marsílio de Pádua desenvolve sua doutrina política para atacar a plenitude do poder papal e defender o Imperador Luís, da Baviera. Trata-se de uma obra que segue parcialmente Aristóteles e apresenta uma nova hermenêutica da teocracia medieval. Neste estudo, utilizaremos a edição crítica latina de Richard Scholz, Fontes Iuris Germanici Antiqui ex Monumenta Germaniae Historic. Hannover, 1932.
} 
natural, nem só a racionalidade dos princípios, mas inclusive o consenso da população deve ser considerado nas legislaçóes e constituiçóes políticas.

Segundo Bayona (2007, p. 177-178), na obra de Marsílio, salientase que a autoridade política são os cidadãos ou quem represente a sua vontade indivisível. Isso não significa ser necessária a presença física de toda a população em algum tipo de assembleia, mas a ação do legislador se faz efetiva pela representação dos membros da comunidade, ao escolher representantes, a saber, pessoas prudentes e experimentadas que façam as vezes de todos e aprovem as leis com a autoridade de todos os cidadáos. As leis, elaboradas mediante consulta à globalidade dos cidadãos e aprovadas, consensualmente, pela mesma, serão mais bem cumpridas e menos protestadas (PADUA, 1932, p. 76). Nosso autor admite a representação (valencior pars) sob duas condiçóes, isto é, quem delega esse poder é a totalidade dos cidadãos (universitas civium) e quem a exerce representa o povo todo, não apenas uma parte. Já foi afirmado que somente com a obra de Marsílio, no século XIV, a ideia de representação chegou a ocupar um lugar distinto no pensamento político (QUILLET, 1970, p. 558). Todavia, a transmissão de poder, de origem divina, a uma ou a várias pessoas por intermédio do povo náo era estranha no pensamento medieval. A exemplo disso, citamos três casos: a cooperação entre a origem divina e a popular no poder, na obra de Joáo Quidort ${ }^{1}$, o caráter representativo do príncipe, em João de Salisbury ${ }^{2}$, e a representação do legislador que também é mencionada por Tomás de Aquino ${ }^{3}$.

Nesta pesquisa, queremos analisar o conceito de valencior pars no filósofo paduano; para tanto, se deverá, inicialmente considerar que Marsílio faz uso de Aristóteles e cita a Política, onde se encontra a expressão to kreîtton méros, significando a parte mais forte ou vencedora, que não possibilita que qualquer governo mude o regime político ${ }^{4}$. Em seguida, é preciso investigar a partir da força da expressão latina valencior pars o duplo significado desse termo nas partes que compóem as obras marsilianas e que correspondem a contextos diversos. Há que se averiguar as diversas interpretaçôes dadas à ideia de representação do autor, iniciando pelas traduções e significações nas línguas modernas. As mesmas produziram raízes que, sem dúvida, influenciaram os

\footnotetext{
${ }^{1}$ De potestate regia et papali, XIX.

${ }^{2}$ Policraticus, IV, 3.

${ }^{3}$ Suma Teológica, I-II, q.90. a.3.

${ }^{4}$ ARISTÓTELES, Politica, $1296 \mathrm{~b}$.
} 
tempos posteriores ao medievo, no entanto, deseja evitar-se possíveis confusóes na interpretação.

Deve-se dizer que não é adequado afirmar que a valencior pars de Marsílio se trata de uma representação popular, fundada sobre um mandato, como o direito democrático. Náo havia a conotação de povo no sentido atual e as alusóes jurídicas em diversas línguas nos reinos, assimiláveis com a universitas civium marsiliana, se referiam sempre a minorias ou grupos cuja capacidade de representação estava ligada ao grau de poder econômico e social. Isso significa que, naquela época, somente eram eleitores, sejam ativos, sejam passivos, pessoas de um certo grau elevado. O Defensor Pacis parece não propor uma teoria de governo representativo, no sentido político moderno de representação, mas no sentido em que o representante tem a função de dar presença ao representado, ou seja, o representante revela o representado, pois atualiza, politicamente, aquele que em si é político potencialmente. Portanto, representar não é agir de modo autônomo do representado, porém, atualizálo, no sentido de constituí-lo em unidade de ação. O legislador representa os interesses gerais, isto é, compartidos e públicos, enquanto distintos dos desejos e interesses particulares ou privados.

O legislador humano é o povo considerado em conjunto ou em sua valencior pars, expressão que acompanha sempre a universitas civium. Essa temática aparece no capítulo XII da prima dictio do Defensor Pacis. Não é fácil delimitar o alcance da globalidade dos cidadãos bem como o da parte preponderante ${ }^{6}$, talvez por ser um conceito deixado voluntariamente impreciso e flexível pelo próprio Marsílio. Para quem considera o autor do Defensor Pacis um republicano, a valencior pars designa, virtualmente, a totalidade da população cidadã de uma civitas. Mas, para os que rejeitam essa análise, entendem que, por meio da valencior pars, o filósofo paduano limita a participação popular, na legislação, a poucas pessoas ou a uma somente (LAGARDE, 1962, p. 155-156). A expressão valencior pars, tida como um

\footnotetext{
${ }^{5}$ Nos autem dicamus secundum veritatem atque consilium Aristotelis $3^{\circ}$ Politice, capitulo $6^{\circ}$, legislatorem seu causam legis effectivam primam et propriam esse populum seu civium universitatem aut eius valenciorem partem, per suam eleccionem seu voluntatem in generali civium congregacione per sermonem expressam precipientem seu determinantem aliquid fieri vel omitti circa civiles actus humanos sub pena vel supplicio temporali." (PADUA, 1932, p.63).

${ }^{6}$ Todas as obras de Marsílio foram traduzidas para a língua portuguesa pelo Prof. José Antônio de C. R. de Souza, conforme acusamos nas referências bibliográficas. A expressão valencior pars foi vertida por "parte preponderante". Sobre o contexto histórico desse período, oferece-nos importante bibliografia. CF. SOUZA, José. As relaçōes de poder na Idade Média Tardia. Marsílio de Pádua, Álvaro Pais e Guilherme de Ockham. Porto: Faculdade do Porto/Porto Alegre: EST, 2009.
} 
enigma (CAPOGRASSI, 1930, p. 581) recebeu significados diferentes, nas suas diversas traduçóes ${ }^{7}$.

A representação corporativa de todos os cidadáos na valencior pars se efetua com ordem a três critérios que especifica Marsílio. O primeiro representa quantitativa e qualitativamente todos os cidadãos; o segundo se mostra na experiência histórica e se refere a um tipo de representação cidadã aos bons costumes das comunidades políticas; o terceiro remete para a autoridade de Aristóteles.

Previté-Orton (1928, p. 49), responsável pela edição crítica do Defensor Pacis, incluiu as palavras personarum et qualitate, omitidas nas ediçóes anteriores. Isso fez com que os pensadores modernos revissem a sua posição a respeito de uma leitura exageradamente democrática do filósofo paduano. A valencior pars, então, emergiu como entidade composta de cidadáos considerados tanto no sentido numérico, quanto por sua qualificada pertença a determinados grupos. Porém, não está clara a posição entre a quantidade e a qualidade das pessoas, como também que grupos sociais representam a totalidade como sua valencior pars, nem se a qualidade é própria das pessoas, ou se refere ao peso das pessoas na comunidade, segundo a sua dignidade ou reputação. Marsílio não esclarece isso, porque não vê necessidade de escolher entre os diversos modos de representação que conhece, sejam as diversas práticas medievais que atendiam a requisitos de quantidade e qualidade, sejam os padróes aristotélicos de organização da civitas. Não afirma igualmente, de modo explícito, que a maioria represente a totalidade. O filósofo de Pádua distingue entre a valentior multitudo dos cidadãos e qualquer minoria de uns poucos.

Compara várias vezes a parte preponderante com um amplo número de pessoas; e inclui, na definição de valentior pars, a todos (omnes personas), exceto aqueles que, por malícia ou ignorância, recusam o acordo com a decisão comum. Nesse sentido, mesmo levando em conta que Quillet (1970, p. 97) privilegie o aspecto qualitativo da valencior pars, a ponto de dar-lhe um significado aristocrático no sentido aristotélico, deve salientar-se a dimensão quantitativa da representação da comunidade política.

\footnotetext{
${ }^{7}$ VASOLI (1960, p. 170) nos recorda as diversas traduçóes de valencior pars: "[...] la meilleure partie (JANET), la plus notable (VALOIS), lélite (WULF), der einflussreichere Teil» (SCHWASS), die stärkere Mehrheit (DEMPF), la parte più valente (LABANCA), la parte piu notevole (PIOVANO), la parte piu cospicua (MOSCA), the effective majority (ALLEN), the dominant part (McILWAIN), the prevailing part (SABINE), the worthier (EDMAN), the weightier (PREVITE-ORTON Y GEWIRTH)". A estas, devem-se acrescentar as propostas por: "LAGARDE, la partie plus valable e por QUILLET, la partie prépondérante, como também parte prevalente (GOMES) e parte preponderante (SOUZA)". Cf. (STREFLING, 2002, p.135).
} 
Um dos critérios exegéticos para entender a valencior pars em Marsílio é reportar-nos a Política de Aristóteles, todavia, parece que isso não oferece maior esclarecimento, uma vez que o paduano cita o texto, sem considerar o conteúdo e o contexto da Política. Diferentemente da obra do estagirita, no Defensor Pacis, a vontade do povo coincide com a decisão da parte preponderante, que representa a todos (totam universitatem representat) e faz as vezes de todos, ao tomar a valencior pars como a mesma comunidade em seu conjunto ${ }^{8}$. A equivalência se repete entre enunciar o princípio do todo e as partes: a universitas civium e sua parte preponderante devem ser tomadas como a mesma coisa ${ }^{9}$. A valencior pars não é, portanto, uma das partes da civitas, mas a comunidade inteira em sua representação. Os elementos que articulam a realidade assim chamada não são indivíduos associados sobre a base de um genérico e ambíguo critério de quantidade ou de qualidade, mas que expressam a constituição coletiva da lei e do Estado, de maneira que a expressáo valencior pars se inscreve na estrutura mesma do corpo social, e sua atuação representa a vontade política de toda a comunidade. A valencior pars é a mesma autoridade legislativa popular e não somente as pessoas encarregadas de preparar ou elaborar as leis, que jamais serão, em absoluto, o legislador. A totalidade dos cidadãos ou sua parte preponderante, enquanto comunidade política, consiste em aprovar as leis, que é outra coisa que idealizá-las ou redigi-las (BAYONA, 2007, p. 180).

Esse conceito marsiliano é de suma importância na comunidade política, pois a representação é necessária, já que é impossível conseguir a unanimidade, e não se deve permitir que a contestação irracional de alguns cidadãos, que, seja por deficiências naturais, seja por malícia e ignorância, sempre estarão em desacordo, dificulte ou impeça de realizar aquilo que convém à comunidade. Faz-se necessário que a valencior pars do povo encarne a autoridade legislativa, porque seria difícil ou impossível concertar os pareceres dos homens maus e pecadores e porque a malícia e a ignorância são defeitos que devem estar excluídos no legislador, que representa o interesse racional, o qual convém ao conjunto e aos interesses concretos dos cidadáos em conflito com ele. Porém, segue sem resposta como se configura a instância da valencior pars para garantir esse ponto de vista superior aos indivíduos e demais partes da civitas, que são incapazes de representar ou substituir o todo. A exegese atual parece não avançar mais na pesquisa do significado de valencior pars, mas, partindo

\footnotetext{
8 "[...] quod pro eodem de cetero suponatur" (PADUA, 1932, p.65).

9 "[...] pro eodem accipienda sunt" (PADUA, 1932, P.63).
} 
desta, averiguar-se-á a possibilidade de caracterizar o pensamento de Marsílio como mais ou menos democrático.

Concordamos com Bayona (2007, p. 181), quando destaca que é necessário ter em vista o critério do contexto a que alude Marsílio, ou seja, aos bons costumes. No entanto, a que costumes honestos ou bons se refere o filósofo paduano? Ainda que a apelação aos costumes formasse parte do artesanal retórico medieval, não é insensato perguntar em que costumes ou instituiçôes de seu tempo e âmbito geopolítico pensava Marsílio? Ignorar essa indicação seria cometer uma grave injustiça com a definição de legislador, bem como com a linguagem política do nosso autor (CONDREN, 1984, p. 75).

Deve-se interrogar também se, por acaso, a parte preponderante é uma adaptação da maior et sanior pars, fórmula presente no direito canônico, usada nas comunidades religiosas e na eleição dos bispos, realizada nos cabidos metropolitanos e presente nas constituiçóes de Barcelona e Pádua, antes de 1239 (MOULIN, 1980, p. 337).Na tradição paduana, a expressão sanior tem dois significados: primeiro, no sentido lato, para delimitar o corpo eleitoral dentro da concepção republicana; segundo, mais técnico, para denotar a maioria qualificada e moralmente vinculante nas votaçóes da assembleia (MARANGON, 1977, p. 110).

Os costumes políticos aludidos por Marsílio devem buscar-se em outros pressupostos de representação. Um seria o governo da Comuna de Pádua, porque as categorias empregadas por Marsílio teriam características paduanas e haviam sido desenvolvidas por correntes precedentes da vida intelectual paduana. Como em outras cidades, o Grande Conselho (Consilius maius) representava toda a cidadania, aprovava a lei e elegia a autoridade. $\mathrm{O}$ podesta equivaleria, em Marsílio, a pars principans ou ao poder executivo, enquanto o Grande Conselho, à valencior pars dos cidadãos, no sentido qualitativo e quantitativo (HYDE, 1966, p. 266). Porém, o termo valencior náo aparece nos estatutos de Pádua. Na linguagem jurídica, era habitual empregar a expressão maior pars, no sentido de maioria numérica dos cidadáos que representa a totalidade. Por outro lado, é paradoxal que Marsílio proponha como modelo, em uma obra dedicada ao Imperador Luís da Baviera e destinada a combater o Papado, as instituiçóes de Pádua, uma comuna caracterizada por sua fidelidade ao partido guelfo ${ }^{10}$ da Província Trevisana, que chegou a oferecer proteção ao rival de Luís da Baviera e candidato do Papa, Frederico de Habsburgo.

${ }^{10}$ As duas palavras "gibelino" e "guelfo" entraram no vocabulário da política italiana no tempo de
Frederico II (1220-50). Derivadas do alemão "Waiblingen" e "Welf", foram gradualmente adotadas 


\section{O CONCEITO DE VALENCIOR PARS}

Deve-se lembrar que o conceito de valencior pars, utilizado no Defensor Pacis, foi inicialmente interpretado pela maioria dos estudiosos, simplesmente como a maioria, até que recentemente um exame dos manuscritos revelou conclusivamente, pela primeira vez, que Marsílio tinha especificado a valencior pars pela quantidade como também pela qualidade (PREVITÉ-ORTON, 1928 , p. 64). O texto original do filósofo paduano diz: “[...] considero essa parte preponderante sob os aspectos da quantidade das pessoas e de suas qualidades no interior da comunidade" 11 Portanto, outros termos além de "maioria" têm sido usados na tradução de valencior, a saber: "melhor", "mais influente", "mais pesada", "mais capaz", "maioria efetiva", "dominante", "preponderante", "meritória”, "mais numerosa e estimável”, "mais notável”, "elite", "mais proeminente" (GEWIRTH, 1951, p. 183).

A maioria dessas traduçóes apresentam problemas em dois sentidos: ou elas superestimam o aspecto qualitativo, às custas do quantitativo, ou elas expressam o significado consequente, ao invés do significado direto de valencior. De fato, o que Marsílio está tentando provar é que a valencior pars das pessoas deve ser dominante no Estado. A determinação do significado do presente tema requer uma análise mais abrangente de suas fontes e da própria interpretação de Marsílio feita até agora, se quisermos afastar o mistério que a envolve ou esclarecer parte desse enigma. Tal análise é justificada não apenas pela sua prevalência sobre o próprio conceito, mas também porque ela deveria ajudar a esclarecer o conceito de povo que, para Marsílio, é a causa eficiente do poder político. Em acréscimo, isso ocupa um importante lugar na história das ideias que constituem a teoria do republicanismo e da democracia.

O termo valencior é, obviamente, relacionado a outros termos semelhantes que haviam sido utilizados, para indicar algum tipo de preponderância política, como valere ${ }^{12}$ e praevalere $^{13}$. A fonte direta da valencior de Marsílio parece, inquestionavelmente, estar na Politica de Aristóteles. William de Moerbeke usa valencior pars para traduzir a expressão

por facçóes rivais florentinas que, na década de 1240, favoreciam o imperador ou o papa (Inocêncio IV). Em 1256, o uso desses termos tinha-se propagado à Itália setentrional, com os partidários papais conhecidos como guelfos e seus adversários como gibelinos. (LOYN, 1991, p. 165-166).

11 "[...] valentiorem inquam partem considerata quantitate personarum et qualitate in communitate illa super quam lex fertur.” (PADUA, 1932, p. 63)

${ }^{12}$ Cícero, De republica, II, XXII, 39.

${ }^{13}$ Tomás de Aquino, Suma Teológica, II-I, q.97, a.3. 
de Aristóteles kreîtton méros ${ }^{14}$; duas passagens nas quais essa expressão aparece são citadas na obra de Marsílio, no curso de sua argumentação em nome da autoridade legislativa do povo ou de sua valentior pars (GEWIRTH, 1951, p. 183-184). Além dos comentários da Política feitos por Alberto Magno, Tomás de Aquino e Pedro de Alverne, valencior parece não ter sido empregada na filosofia política medieval anterior a Marsílio; o termo não foi muito usado depois dele, mas, onde aparece há uma presença quase certa do mesmo. Para Aristóteles, entretanto, kreîtton significa apenas o "politicamente mais forte", enquanto, para Marsílio, este não é um significado direto, mas consequente de valencior. Damiata (1983, p. 169) afirma que se trata de uma parte que substitui a universitas civium com idêntica autoridade e, substancialmente, com igual utilidade. Para entender o seu significado direto, nós temos que levar em conta como o próprio Marsílio a define.

O filósofo de Pádua apresenta três especificaçôes distintas, embora mutuamente coerentes, da valencior pars. A primeira é através de conceitos racionais, considerando "[...] a quantidade e a qualidade das pessoas naquela comunidade, para a qual a lei é feita" (PADUA, 1932, p. 63). A segunda especificação é pela experiência histórica, a saber: "[...] a parte preponderante dos cidadãos deve ser considerada de acordo com o costume honroso da política" (PADUA, 1932, p. 64). A terceira é pela autoridade: "[...] a valencior pars deve ser entendida de acordo com a visão de Aristóteles na Política, Livro VI, capítulo 2" (PADUA, 1932, p. 64). Neste estudo, vamos examinar os significados de quantidade e qualidade atribuídos a valencior pars.

\section{A VALENCIOR PARS ENQUANTO QUANTIDADE}

A especificação qualitativa por Marsílio de valencior ao quantitativo deixou grande impressão aos comentadores, que a levaram para o extremo oposto da interpretação igualitária, democrática e majoritária sobre o seu posicionamento. Em consequência disso, tem sido amplamente desconsiderado não somente que Marsílio menciona a quantidade como a qualidade, mas também o fato de que quase todas as suas elucidaçôes consecutivas são equivalentes. Ele inicia com uma afirmação que implica unanimidade: as leis devem ser elaboradas pelo "conjunto dos cidadáos". Contudo, por ser a unanimidade difícil ou impossível de atingir, ele adiciona a pars valencior como alternativa: as leis devem ser feitas pela totalidade dos cidadáos ou a

${ }^{14}$ Politica, $1296 \mathrm{~b}$. 
parte preponderante que representa a totalidade, pois não é fácil que todas as pessoas concordem com uma decisão, porque determinados homens têm uma natureza deturpada, discordando com a decisão comum, através da malícia pessoal ou ignorância (PADUA, 1932, p. 65). A valencior pars compreende todas as pessoas, exceto certos homens de natureza deformada. Esse conceito excepcional de deformação (orbatam) contém a mesma restrição de universalidade que encontramos no primeiro princípio de Marsílio, segundo o qual "[...] todos os homens náo deformados naturalmente desejam uma vida suficiente" (PADUA, 1932, p. 17). A relação com esse princípio da autoridade legislativa da valencior pars é direta: a diferença quantitativa entre o corpo dos cidadãos e a parte preponderante constitui-se superior em relação às poucas pessoas deformadas. A valencior pars compreende, assim, a grande maioria esmagadora dos cidadãos.

O significado quantitativo de valencior pars é demonstrado pelas expressóes usadas por Marsílio como sinônimos. A valencior pars é a maioria - plurimi (PADUA, 1932, p. 68) - pluralitas (PADUA, 1932, p. 63), isto é, o corpo dos cidadãos com respeito à maioria dos seus membros (secundum eius plurimum) (PADUA, 1932, p. 63), contra qualquer parte menor, é a parte mais ampla (pars amplior), mais abrangente dos cidadãos, o número que excede em contraposição a alguns (superflua pluralitas). Marsílio, dessa forma, usa o termos muitos (plures e plurimi) como sinônimo de valencior. Em determinado ponto, ele explica que o termo plures deve ser empregado tanto no sentido positivo, "muitos", como do comparativo "mais" (parte valenciori sive maiori) (PADUA, 1932, p. 82, 424). Essa parte preponderante compreende não apenas uma maioria simples, mas uma maioria dominante. A mesma conclusão do filósofo paduano também surge do uso da máxima "o todo é maior que a sua parte". Concordamos com a interpretação de Gewirth (1951, p. 186), ao afirmar que o todo significa a universitas civium, e que a parte significa a valencior pars, contudo, mais propriamente no sentido de que o todo significa o conjunto dos cidadáos ou sua parte preponderante, que devem ser interpretados como a mesma coisa e náo como partes separadas (quacumque sui parte seorsum) (PADUA, 1932, p. 70, 74). Quantitativamente, em consequência, Marsílio não pensa na valencior pars como sendo distinta da universitas; ao contrário, elas são quase idênticas.

Qual é então o propósito dessa visão quantitativa da parte preponderante dos cidadãos, que abrange a todos, exceto os poucos deformados que se recusam em concordar com o julgamento comum? Isso náo envolve a obrigatoriedade 
da concordância, pois, como vimos, Marsílio reserva expressamente aos cidadãos o direito de protestar contra as recomendaçóes dos sábios eleitos, bem como corrigi-los e rejeitá-los inteiramente ${ }^{15}$. Além disso, uma das objeçôes que ele tem em vista, contra o seu próprio posicionamento, é que "[...] é difícil ou impossível que as pessoas corrompidas e pouco inteligentes concordem em seus julgamentos, o que não é o caso, com relação aos poucos e virtuosos. É, portanto, mais útil que a lei seja estabelecida por poucos, do que pelo conjunto dos cidadãos ou por um número excedente deste " (PADUA, 1932, p. 69). A réplica de Marsílio admite que é mais fácil a poucos do que para muitos concordarem, porém, insiste que isso é ratificado pela superioridade em julgamento do conjunto dos cidadáos, em detrimento dos poucos (PADUA, 1932, p. 74). A concordância, como tal, não é a consideração primeira na visão de Marsílio, pelo menos não no seu propósito inicial, com relação ao legislativo e a outros julgamentos do conjunto dos cidadáos. Nesse sentido, foram os monarquistas que enfatizaram a importância da concordância como tal; a concepção marsiliana de todas as pessoas detendo autoridade suprema é o objetivo do seu argumento de que muitos discordariam.

A relação da valencior pars com o conjunto dos cidadãos é, por conseguinte, bem diferente daquela que o Concílio Geral concebeu na Cristandade, ou os príncipes eleitores, ou o Senado para o povo romano. Em cada caso, há uma relação de "representação"; ademais, há uma semelhança presumida entre as razões de Marsílio, para invocar a valencior pars e as razóes dadas no Direito Romano para a convocação do Senado. Mas essa semelhança é apenas aparente, apoiando-se por um erro de interpretação do conceito do paduano. Dois textos do Direito Romano narram que a população romana tinha aumentado tanto, que era difícil reuni-la num único grupo; por essa razão, a criação de leis voltou ao Senado (LAGARDE, 1970, p. 196). A relação quantitativa da população com o Senado é, dessa forma, a de muitas pessoas com muito poucas, e a consideração principal, que motiva a transmissão da autoridade legislativa das primeiras para as segundas, é a reunião física em um único grupo. A relação quantitativa do povo, segundo Marsílio, com a valencior pars, por outro lado, é, como vimos, a de todos com quase todos, e a consideraçáo da transmissão de autoridade para o último é a de concordância voluntária. Essa ênfase é, sem dúvida, correspondente com o voluntarismo de Marsílio em toda a sua doutrina. A dificuldade da assembleia física não é,

$15 \mathrm{O}$ conjunto dos cidadãos ou sua parte preponderante pode reclamare, repellere e spernendum (PADUA, 1932, p. 75-76). 
absolutamente, invocada pelo filósofo paduano em conexão com a valencior pars. É somente em conexão com a descoberta das leis pelos relativamente poucos especialistas que nosso autor invoca uma consideraçáo um tanto semelhante à romana. Todavia, essa consideração não é a que a população seja grande demais para se reunir, mas a de que todos os cidadáos despendessem o seu tempo nas investigaçôes iniciais de possíveis leis, a realização das funções necessárias para a comunidade seriam indevidamente perturbadas (PADUA, 1932, p. 72). Contudo, a descoberta à qual essas investigaçóes levam não é, como vimos, a sanção legislativa, tấo pouco são os especialistas que Marsílio quer dizer, na valencior pars. Pelo contrário, ele expressamente delega que é a assembleia do conjunto dos cidadãos que deve eleger a consideração dos conselhos dos mais sábios e a aprovação das leis finais ${ }^{16}$.

Pela mesma razão, é necessário distinguir os tipos de representação aos quais Marsílio se refere. Os especialistas que elaboraram a legislação proposta representam o conjunto dos cidadáos ${ }^{17} \mathrm{Da}$ mesma maneira que, num concílio geral, se determinam assuntos em matéria de fé, representando o conjunto dos fiéis ${ }^{18}$, no sentido de que eles são eleitos pela maioria, para realizar uma função específica, assim igualmente representam seu lugar e autoridade. A parte preponderante dos cidadãos, por outro lado, representa a totalidade dos cidadáos, no sentido de que a anterior abrange, e é interpretada como a mesma coisa ${ }^{19}$. Em cada caso, o que representa pode agir como o representado, e a parte preponderante, longe de ser eleita pelo conjunto dos cidadãos, é quase esse conjunto, no sentido numérico literal. E, enquanto a autoridade representativa dos legisladores especialistas e do concílio geral é seriamente limitada, uma vez que as suas decisóes devem ser ratificadas pela universitas, ou legislador no sentido estrito, não há limite algum sobre a parte preponderante quanto à universitas, porque a autoridade anterior é coexistente à posterior.

$\mathrm{O}$ aspecto quantitativo da parte preponderante, como discutido até agora, emerge claramente das afirmativas do autor do Defensor Pacis. A sua primeira preocupação quanto ao aspecto quantitativo é com a situação final,

\footnotetext{
16 "[...] ingenerali civium congregatione." "omnium congregata multitudo." "ab omnibus simul congregatis civibus"; "in universitate civium congregata"; "per auditum et consensum universae multitudinis"; in universali civium congregatione." (PADUA, 1932, p. 74-75).

17 “[...] vincem et auctoritatem universitatis civium repraesentantes."(PADUA, 1932, p. 68).

18 “[...] vicem universitatis fidelium repraesentantes"(PADUA, 1932, p. 393).

19 "[...] pars valencior, quae totam universitatem repraesentat";" hoc autem fieri optime per civium universitatem tantummodo, aut eius valenciorem partem quod pro eodem de cetero supponatur."(PADUA, 1932, p. 65).
} 
quando uma decisão comum já foi tomada na assembleia dos cidadáos, porém, todos aceitaram, exceto os deformados ou corrompidos. Contudo, se nós perguntarmos qual é a quantidade específica de votos, dentro dessa maioria dominante, isoladamente ou junto a fatores qualitativos, para tomar uma decisão em primeiro lugar, nenhuma informação específica é dada por Marsílio. Nós encontraremos indicaçóes desse fator característico específico, se tratarmos das suas duas outras especificações da valencior pars, mas ele próprio não apresenta nenhuma. $\mathrm{O}$ mais próximo que ele chega de tal indicação é na sua afirmação de que os sábios legisladores serão eleitos por cada uma das partes principais da civitas (estado), mas, de acordo com a proporção de cada um (PADUA, 1932, p. 76-77). Que essa proporção não seja, entretanto, meramente quantitativa se demonstra pelo fato de que a democracia esteja classificada dentre as formas doentes de governo, porque não está de acordo com a proporçáo adequada (PADUA, 1932, p. 38). Mas que envolve, pelo menos, uma maioria numérica é mostrado nos textos considerados até agora.

O autor do Defensor Pacis está essencialmente preocupado com o estabelecimento do princípio de que a autoridade do legislativo se apoia em toda a população, ao invés de uma ou poucas constituições monárquicas ou oligárquicas. Ele não especifica o método ou proporçóes exatas pelos quais a população deve chegar a essas decisóes, já que estas são variáveis. Ele insiste em que as decisôes sejam alcançadas livremente, e que elas tragam a sanção de todo o corpo de cidadáos, ou de todos, exceto uns poucos, os quais, apesar da sua posição inicial, aceitam e apoiam a decisão comum.

\section{A VALENCIOR PARS ENQUANTO QUALIDADE}

Por qualidade Marsílio entende tanto as diferenciaçóes funcionais entre as diferentes partes da civitas (estado), quanto as características pessoais dos cidadáos. Ele usa o termo no sentido anterior, quando repete o alerta de Aristóteles ${ }^{20}$ contra o crescimento desproporcional de qualquer parte do estado, em quantidade e qualidade (PADUA, 1932, p. 92). O filósofo patavino usa o termo em sentido último, quando menciona a fraqueza dos cristãos primitivos em quantidade e qualidade, pois eles eram imaturos e facilmente manipulados (PADUA, 1932, p. 329, 367, 418), assim como quando se refere, depreciativamente, à qualidade dos padres (PADUA, 1932, p. 471). Embora ele especifique a parte preponderante pela quantidade e qualidade

${ }^{20}$ Politica, $1302 \mathrm{~b}$. 
das pessoas (PADUA, 1932, p. 63), a diferença qualitativa está na relação de tais discriminaçôes como, no caso da votação, se referem essencialmente às diferenças entre as partes da civitas. É a partir desse ponto de vista, que divide as partes entre os notáveis e os vulgares, que são partes no sentido estrito (simpliciter) ou no sentido amplo (large), respectivamente, por que os últimos são funções (officia) necessárias ao estado, de acordo com a visão de Aristóteles $^{21}$ (LABANCA, 1882, p. 137).

Dessa forma, Marsílio aqui repete a posição aristocrática do melhor estado possível do estagirita, embora ele não o siga, na negação da cidadania dessas partes necessárias, tornando-as escravas. É com base em um ponto de vista semelhante, entretanto, que ele condena a democracia no sentido aristotélico como a regra apenas do vulgo e não de acordo com a proporção adequada. O vulgus numericamente iria sobrepujar a honorabilitas; é por essa razão que os considerados qualitativos são invocados. A suposição subjacente de Marsílio é aqui a mesma de Aristóteles; ela é igualmente baseada na experiência real das comunas italianas. A suposição é de luta de classes: a plebe (vulgus) e os notáveis (honorabilitas) - substituem os vários grupos populares, os magnatas, por um lado, e o clero, por outro - vai cada um agir como uma unidade política homogênea, para desenvolver seu próprio poder econômico e reduzir o do outro. Com o intuito de evitar certo particularismo é que Marsílio mistura quantidade com qualidade. Mas essa proporção produz um efeito tanto quanto a oligarquia ou a aristocracia como o tipo aristotélico de democracia. Marsílio sustenta mais propriamente a forma de governo na qual cada cidadáo participa de acordo com a sua posição e capacidade ou condição. O grau de participação no poder político de cada cidadão dependerá, portanto, de sua hierarquia (gradus) (PADUA, 1932, p. 64), e esta, por sua vez, é determinada pelo grupo funcional ao qual ele pertence. Nesse modo de diferenciação do estado ou do povo em categorias superiores e inferiores, ou ordens, ou status, o filósofo de Pádua se alinha com outros aristotélicos e, na realidade, com toda a orientação do pensamento medieval.

O conteúdo específico dessas diferenciações qualitativas, como Marsílio as vê, parece também derivar, pelo menos em parte, de Aristóteles. Na Política, é declarado que cada estado consiste em qualidade e quantidade. A qualidade significa: liberdade, prosperidade, educação, boa procedência; a quantidade se refere aos números superiores da multidão ${ }^{22}$. Essa sentença ocorre logo após

\footnotetext{
${ }^{21}$ Politica, 1328a.

${ }^{22}$ Politica, 1296b.
} 
outra que menciona a kreîtton méros (valencior pars) de Marsílio (PADUA, 1932, p. 71). Parece, assim, uma inferência plausível que ele esteja se referindo a essa passagem, na especificaçáo de sua valencior pars como quantidade e qualidade. Certamente ele usa a especificação para um fim diferente daquele de Aristóteles, visto que o último vai além, para indicar quais os tipos de constituiçôes são mais adequadas aos vários estados, de acordo com as proporçóes e as características qualitativas de seus habitantes ${ }^{23}$. A constituição do estado marsiliano não tem a variabilidade que Aristóteles aponta. Marsílio, explicitamente, recusa permitir qualquer caso onde uma constituição oligárquica fosse naturalmente convocada (PADUA, 1932, p. 74).

Todas as características que Aristóteles enumera nessa passagem, porém, receberam a consideração de Marsílio. A liberdade é utilizada como a caracterizaçáo de todos os cidadãos (PADUA, 1932, p. 16). A procedência é enfocada apenas negativamente, pois ele argumenta contra a sucessão hereditária, alegando que as qualidades virtuosas não são necessariamente herdadas. $\mathrm{O}$ caso é parcialmente idêntico com relação à prosperidade, porque ele insiste que homens pobres e virtuosos devem ter a oportunidade de se tornarem governantes (PADUA, 1932, p. 82); e uma grande parte da sua polêmica com o papado está baseada na sua preocupação com a riqueza (PADUA, 1932, p. 259). Além disso, a parte financista do estado é classificada entre a plebe, em contraste com Aristóteles, que designa seu análogo, uma abundância de dinheiro, as classes superiores ${ }^{24}$ na mesma lista sêxtupla das partes do estado que Marsílio adota. Por outro lado, no entanto, ele aplica o critério da prosperidade, através do conceito de ócio, que é constantemente invocado. Esse ócio para funçôes liberais é o que distingue os cidadãos dos escravos (PADUA, 1932, p. 16), mas também é o ócio que distingue aqueles cidadãos, que participam de todas as atividades deliberativas do estado, daqueles envolvidos com as tarefas mecânicas e que estão preocupados em satisfazer as necessidades da vida pelo trabalho. Marsílio, como Aristóteles, pressupóe, desse modo, a divisão da cidade em um pequeno grupo de ociosos e uma grande quantidade de homens ocupados no trabalho mecânico. As suas referências para o tipo descrito por Aristóteles, "educação", seguem linhas semelhantes à guisa da "prudência", que é concebida como concomitante ao ócio e que é uma das principais qualidades do governante perfeito (PADUA, 1932, p. 78-79).

\footnotetext{
${ }^{23}$ Politica, 1296 b.

${ }^{24}$ Política, 1392a.
} 
Ainda assim, Marsílio mantém essa posição no sentido estrito do estado real de Aristóteles. A visão de Aristóteles no que concerne ao ócio é ambivalente: ele enfatiza a importância de os melhores cidadáos terem capacidade para realizar o ócio ${ }^{25}$ e, sobre esse pretexto, ele exclui os fazendeiros e os artesãos da cidadania, no seu estado ideal. Mas, por outro lado, nos seus textos menos normativos, é precisamente a falta de ócio que ele defende como uma condição necessária para o sucesso do estado democrático, já que sua preocupação com a obtenção das necessidades da vida os força a governar através de leis $^{26}$. A atitude de Marsílio é diferente. Ele insiste em que os menos letrados, ou aqueles que não têm condiçóes para exercer funçóes liberais, deveriam, não obstante, compartilhar, visto que eles participam no entendimento e julgamento dos assuntos práticos, embora não igualmente ou na mesma proporção daqueles que dispóem de tempo livre (PADUA, 1932, p. 73). Como vimos no caso da sua concepção de cidadáo, ele não tem uma demarcaçáo tão estrita entre os ociosos e não ociosos, no exercício das funçôes políticas, como têm outros aristotélicos. É, entretanto, a combinação de prudência e ócio que, para Marsílio, constitui o critério qualitativo, o qual determina a parte preponderante dos cidadãos.

\section{Consideraçóes finais}

Marsílio não indica as proporçôes precisas pelas quais o povo (vulgus) deve se opor aos notáveis (honorabilitas), nem o número proporcional de cidadãos sábios e prudentes. Tais proporçôes foram estabelecidas por Aristóteles e Cícero, dentre outros. Também a doutrina canônica da melhor e maior parte (maior et sanior pars) de um capítulo da catedral, para a decisão das eleiçôes episcopais, foi importante e influenciou o filósofo paduano na sua compreensão de quantidade e qualidade da valencior pars. Há, na verdade, importante semelhança entre as duas concepçóes. As duas partem da noção de unanimidade e foram invocadas, porque a unanimidade provou ser inatingível, cada uma delas envolvendo uma combinação de qualidade e quantidade. Além do mais, o próprio Marsílio alude à parte melhor dos sacerdotes e da totalidade dos fiéis, embora ele não identifique essa concepção com a valencior pars. Um outro fator é que a parte maior e melhor (maior et sanior pars) foi chamada, nos estatutos de Pádua, como regulamento das eleiçôes governamentais pelos

\footnotetext{
${ }^{25}$ Politica, 1273a.
}

${ }^{26}$ Política, 1292b. 
gastaldiones, corporação de notáveis, à qual Bonmatteo dos Mainardini, o pai de Marsílio, provavelmente pertenceu (GEWIRTH, 1951, p. 194).

Apesar desses pontos em comum, há uma fundamental diferença na interpretação das duas concepçóes. Não somente a parte maior e melhor se deslocou da unanimidade dos padres e da populaçáo para um voto restrito apenas aos padres, mas mesmo entre os últimos, a sua solidez, consistindo na própria autoridade, zelo e mérito, tinham um valor maior que o número dos indivíduos. A relação entre os maiores e os melhores foi concebida não só como capacidade de concordarem, mas igualmente de se oporem, negando-se que, onde o número é maior, o zelo é presumivelmente melhor, de sorte que, no lugar disso, se insistiu em que os melhores são em pequeno número. Desse modo, o Papa Gregório X determinou, em 1274, que uma votação de dois terços deveria decidir uma eleição, embora a possibilidade de anulação não fosse desconsiderada sob o ponto de vista qualitativo e legal (GEWIRTH, 1951, p. 194).

A interpretação da valencior pars, por outro lado, compreende os aspectos quantitativos e qualificativos com plena concordância. Isso é evidenciado pelo uso que o autor do Defensor Pacis faz da máxima "o todo é maior que a parte". Ele defende que isto é verdadeiro, tanto com respeito à sua magnitude ou quantidade, como à virtude prática e ação (PADUA, 1932, p. 70). Destarte, um aumento na quantidade trará consigo um aumento no valor qualitativo e, através disso, ele responde aos argumentos no sentido de que muitos que são menos instruídos não são bons juízes da legislação quanto os poucos que são mais instruídos: "[...] o número dos menos instruídos poderia ser aumentado a ponto de que eles julgassem essas coisas igualmente tão bem ou melhor, que os poucos que são instruídos" (PADUA, 1932, p. 73). Além disso, "[a] totalidade dos cidadãos é mais ampla, e consequentemente o seu julgamento é mais seguro, do que a de alguma parte tomada separadamente"(PADUA, 1932, p. 73).

Isso não é surpreendente, considerando que a valencior pars tenha sido interpretada unicamente em termos quantitativos, por muitos séculos, até que a pesquisa acadêmica restaurasse a palavra qualidade no texto de Marsílio. $\mathrm{Na}$ verdade, essa quantidade não é a unidade individual idêntica, mas a de grupos; ainda assim, Marsílio concebe a igualdade qualitativa ou superioridade de um grupo, em relação ao outro, como sendo determinada por suas respectivas quantidades. Ele coloca duas limitaçóes sobre essa determinada quantidade, o que, de outra forma, levaria a uma aceitaçáo da democracia como definida pela tradição aristotélica. Uma dessas limitaçóes é o particularismo na sua visão de democracia. $\mathrm{Na}$ sua concepção de desenvolvimento, nas comunidades 
primitivas, a qualidade nem sempre acompanha a quantidade (PADUA, 1932, p. 14). Além destas, a ênfase de sua defesa da valencior pars dos cidadáos como legislador está alinhada com o que os defensores da democracia tinham sustentado. Portanto, é incorreto inferir, a partir de sua introdução da qualidade, que a valencior pars corresponde a ideias antidemocráticas de Aristóteles. Isso parece não levar em conta que a valencior pars inclui o vulgus, ou seja, o demos de Aristóteles, e que os argumentos em nome da valencior pars se opóem, explicitamente, à visão antidemocrática de que somente os especialistas deveriam ser o legislador. Poucos são os vilóes e muitos, os heróis, na obra de Marsílio (PADUA, 1932, p. 62, 74).

Contra a doutrina aristocrática de que os poucos virtuosos deveriam legislar, Marsílio defende o direito dos outros cidadãos (PADUA, 1932, p. 67), os homens de intelecto mais humilde (PADUA, 1932, p. 68), os agricultores, os artesãos e outros similares, os quais não devem ser chamados de incapazes, mas devem ser contados entre os bons, já que os cidadáos não são nem maus nem incapazes de discernimento, na maioria dos casos e na maior parte do tempo, uma vez que todos ou a maioria tem mente e raciocínios saudáveis. Isso é possível ver na sua defesa da integridade da maioria dos cidadáos como uma refutação indireta à doutrina canônica da parte maior e mais saudável do clero como sendo a única forma apropriada de eleger bispos. Longe de corresponder às ideias antidemocráticas de Aristóteles, essa defesa da valencior pars opóe-se diretamente a tais ideias; ela está baseada naquelas breves passagens da Política, nas quais Aristóteles vagamente defende a democracia que ele condena, no restante de sua obra. Em termos das distinçóes das constituiçôes de Aristóteles, a civitas de Marsílio está mais próxima da democracia (GEWIRTH, 1951, p. 196).

Concluindo este estudo, cabe-nos apontar outra interpretação da valencior pars de Marsílio, a saber: considerando alguns textos da segunda parte do Defensor Pacis e o Defensor Minor, outra obra do paduano, deve-se dizer que nosso autor se inclina a identificar o legislador, portanto, a valencior pars com o imperador ou governante. Trata-se de uma outra tese que nos remete a perspectivas diversas de tudo que se asseverou até agora (QUILLET, 1970, p. 97). Por conseguinte, entendemos ser necessário continuar nossa pesquisa sobre esse tema, porém, quiséramos, nestas linhas, apresentar à reflexão ética e política da atualidade o conteúdo que envolve esse tema enigmático, todavia importante, visto que a representação política é o esteio das grandes decisóes que norteiam a sociedade e o estado. 
STREFLING, Ricardo. Valencior pars in the Defensor Pacis of Marsilius of Padua. Trans/ Form/Ação, Marília, v. 35, p. 225-244, 2012. Edição Especial.

\begin{abstract}
Marsilius of Padua (1280-1343) was a philosopher of the Middle Ages who wrote two books of political philosophy that have influenced modernity. This study analyzes the term valencior pars in the Defensor Pacis. Marsilius appears to define this preponderant part of the population as representing that part of the citizenry who do not have a debilitated nature. This suggests that the valencior pars is a much a qualitatively superior as a numerically greater part of the citizenry. The appeal to a mixture of quantitative and qualitative considerations was familiar in the context of the medieval church, which habitually supported the greater and more reasonable part (maior et sanior pars) of electoral institutions. Marsilius also suggests, however, that the valencior pars can be identified with this honored custom of government. It seems then, that the valencior pars is whatever part of the citizenry whose electoral decision is decisive. In this, Marsilius is at one with Aristotle's original analysis.
\end{abstract}

KEYWORDS: Marsilius of Padua. Representation. Prevailing part. Politic.

\title{
REFERÊNCIAS
}

ARISTÓTELES. Politica. Edição bilíngüe. Lisboa: Veja, 1998.

BAYONA AZNAR, Bernardo. Religión y poder. Marsilio de Padua: La primera teoria laica del Estado? Madrid: Biblioteca Nueva, 2007.

CAPOGRASSI, A. In torno a Marsilio da Padova. Rivista Internazionale di filosofia del diritto, X, p. 579-90, 1930.

CICERO. De Republica. Trad. J. Guillen. Madrid: Tecnos, 1986.

CONDREN, Conald. Rhetoric, Historiography and Political Theory: Some Aspects of the Poverty Controversy Reconsidered. The Journal of Religious History, XIII/1, p. 15-34, 1984.

DAMIATA, Marino. Plenitudo Potestatis e Universitas Civium in Marsilio da Padova. Firenze: Studi Francescani, 1983.

GEWIRTH, Alain. Marsilius of Padua and Medieval Political Philosophy. New York: Columbia University Press, 1951.

HYDE, J. K. Padua in the Age of Dante. New York: Manchester University Press, 1966.

JOÃO QUIDOR. De potestas regia et papali. Trad. De Boni. Petrópolis: Vozes, 1989.

JOÃO SALISBURY. Policraticus. Roma: Laterza, 1968.

LABANCA, B. Marsilio da Padova e Martino Lutero. In: Nuova Antologia, série II, v.XLI, 1882, p. 209-227.

LAGARDE, Georges de. La Naissance de L’Esprit Laïque au Déclin du Moyen Âge. v.III. Louvain-Paris: Éditions Nauwelaerts, 1970. 
LOYN, Henry. Dicionário da Idade Média. Trad. Álvaro Cabral. 2.ed. Rio de Janeiro: Jorge Zahar, 1991.

MARANGON, Paolo. Marsilio tra Preumanesimo e cultura delle arti. Ricerca sulle fonti padovane del primo discorso del "Defensor Pacis". Medioevo. Pádua, v.3, p.89-119, 1977.

MOULIN, Léo. Une source méconnue de la philosophie politique marsilienne: l'organisation constitutionnelle des ordres religieux. Medioevo, Pádua, v. 5, p. 337-346, 1980.

PADUA, Marsilius. Defensor Pacis, Fontes Iuris Germanici Antiqui in Usum Scholarum, ex Monumentis Germaniae Historicis, separatim editi. Hannover: Richard Scholz, 1932.

O Defensor da Paz. Tradução e notas de José Antônio Camargo Rodrigues de Souza. Introd. de J.A. Souza, F. Bertelloni e G. Piaia. Petrópolis: Vozes, 1997.

PRÉVITÉ-ORTON, C. W. The Defensor Pacis of Marsilius of Padua. Cambridge: Cambridge University Press, 1928.

QUILLET, Jeannine. La Philosophie Politique de Marsile de Padoue. Paris: Vrin, 1970.

SOUZA, José Antônio C.R. As relaçôes de poder na Idade Média Tardia. Marsílio de Pádua, Álvaro Pais e Guilherme de Ockham. Porto/Porto Alegre: Faculdade de Letras da Universidade do Porto/ EST, 2009.

STREFLING, Sérgio R. Igreja e Poder. Plenitude do Poder e Soberania Popular em Marsilio de Pádua. Porto Alegre: EDIPUCRS, 2002.

TOMÁS DE AQUINO. Suma Teológica. Porto Alegre: Sulina, 1980.

VASOLI, Cesare. Introdução. In: PADOVA, Marsilio. Il Difensore della Pace. Torino: Torinese, 1960. 
STREFLING, S. R. 